\title{
Conyza (Asteraceae): una valoración crítica basada en las poblaciones de Cataluña, España
}

\author{
S. PYKE \\ Jardí Botànic de Barcelona, Consorci de Museus de Ciències Naturals de Barcelona, \\ c. Dr. Font i Quer, 2, ES-08038 Barcelona, España \\ ORCID iD. S. PYKE: https://orcid.org/0000-0001-8030-3519 \\ E-mail: spyke@bcn.cat \\ Editor: L. Sáez \\ Recibido 11 octubre 2019; aceptado 15 enero 2020; publicado on line: 31 agosto 2020
}

\begin{abstract}
Conyza (Asteraceae): A critical evaluation based on populations in Catalonia, Spain.- The genus Conyza is examined with a view to providing a fresh look at its diversity and classification in NE Spanish territory, Catalonia in particular. Each taxon is briefly described and commented on, and a new key including both past and extant species has been elaborated. Two infraspecific taxa: C. canadensis var. glabrata and C. bonariensis var. angustifolia, formerly largely ignored, have been recognised, and the identity and status of other taxa occasionally recorded from the region is also discussed.
\end{abstract}

Key words: Catalonia; Compositae; Conyza; Erigeron; Iberian Peninsula; keys; synonyms; taxonomy.

\section{Resumen}

Conyza (Asteraceae): Una valoración crítica basada en las poblaciones de Cataluña, España. - Se examina el género Conyza para entender mejor la diversidad infragenérica en el NE de España, principalmente en Cataluña. Cada taxon se trata con una breve descripción y comentarios, además se ha elaborado una clave dicótoma que incluye tanto las especies presentes actualmente como las presuntamente desaparecidas. Se reconocen dos táxones infraespecíficos poco conocidos: C. canadensis var. glabrata y C. bonariensis var. angustifolia, además de analizar la identidad y el estatus de otros táxones a veces citados.

Palabras claves: Cataluña; clave; Compositae; Conyza; Erigeron; Península Ibérica; sinónimos; taxonomía.

\section{Cómo citar este artículo / Citation}

Pyke, S. 2020. Conyza Less. (Asteraceae): una valoración crítica basada en las poblaciones de Cataluña, España. Collectanea Botanica 39: e05. https://doi.org/10.3989/collectbot.2020.v39.005

\section{Copyright}

(C) 2020 CSIC. This is an open-access article distributed under the terms of the Creative Commons Attribution 4.0 International (CC BY 4.0) License. 


\section{INTRODUCCIÓN}

El género Conyza Less., alóctono en Europa y la Región Mediterránea, presenta no pocas dificultades a la hora de abarcar su clasificación. Los táxones presentes en la Península Ibérica se consideran neófitos naturalizados, además de ser en mayor o menor medida malas hierbas, que compiten con otras especies pioneras - nativas o no- como el omnipresente Symphyotrichum squamatum (Spreng.) G. L. Nesom [Aster squamatus (Spreng.) Hieron.], planta antiguamente incluida dentro de Conyza. Al tratarse de especies bien establecidas y extendidas por el territorio, no se puede contemplar su erradicación. Queda, pues, la tarea de entender pautas de convivencia con estas plantas que colonizan los terrenos baldíos, alterados por el hombre, con tanto éxito. Aunque hoy en día se encuentran distribuidas de manera cosmopolita por las regiones tropicales y templadas del mundo, su origen evidentemente se remonta al continente americano. En lo que se refiere a su dispersión a largas distancias, todo parece indicar que los principales vectores han sido el viento (Wurzell, 1988) y la actividad antrópica.

En cuanto a la taxonomía de este grupo de plantas, hay que referirse a la complejidad de la subtribu Conyzinae Horan. (tribu Astereae Cass.), donde se incluyen Erigeron L., Conyza y algunos géneros más pequeños (Nesom, 2008). Sin embargo, algunos investigadores, por ejemplo Noyes (2000), no ven suficiente justificación (ni morfológica ni molecular) como para separar Conyza de Erigeron, y prefieren combinar ambos dentro de Erigeron, siendo éste el género basal. Este criterio lo adoptó Greuter (2003, 2006-). No obstante, ambas posturas son defendibles. Stace (2010), quien reconoce cuatro especies existentes en las Islas Británicas, hace el siguiente resumen: "Conyza is a complex and difficult genus, the British representatives being small distinct samples of a wide spectrum of more continuous variation in America. Although separable, Conyza and Erigeron would be better amalgamated if they do not form two distinct evolutionary lines". Aquí he optado por respetar Con$y z a$ (un nom. cons.) en consonancia con trabajos muy consultados de nuestra región que incluyen Flora europaea (Tutin et al., 1976), Flora iberica (Castroviejo, 1986-2019), Flora dels Països Catalans (Bolòs \& Vigo, 1984-2001) y otras floras regionales.
En términos generales, las especies de Erigeron presentan los capítulos solitarios o en corimbos de pocos capítulos. Éstos contienen un gran número de flores hermafroditas (las internas). En cambio, las especies del género Conyza presentan en su mayoría un número elevado de capítulos organizados en corimbos o panículas con un número reducido de flores hermafroditas en cada capítulo. Existen híbridos entre ambos géneros.

Nesom (2008) considera que el género Conyza, al que incluye dentro de Erigeron, sea, como mínimo, bifilético, y reconoce la posibilidad de que el género Erigeron, tal y como se ha empleado en las últimas décadas, tampoco sea monofilético. Este mismo autor divide las especies de Conyza en dos grupos, los cuales corresponden a secciones de Erigeron según sus autores: sect. Caenotus Nutt., en la cual se ubica $C$. canadensis (L.) Cronq., y sect. Conyza (Less.) Baill., donde encontramos las demás especies que nos conciernen.

En esta contribución, se valora el trabajo de Bolòs \& Vigo (1996), en el cual recogen cinco zamarragas (coniza en catalán; fleabane o horseweed en inglés) presentes en los países catalanes. En adición, se reconoce una variedad distinta de $C$. canadensis hasta ahora ignorada: var. glabrata (A. Gray) Cronq., además de comentar $C$. daveauana Sennen y tratar brevemente el tema de los híbridos. Se descarta - por falta de testigos de herbario-C. blakei (Cabrera) Cabrera, tal como indicó Laínz (2002). Esta especie, no obstante, está presente en el sur de Francia (Languedoc-Roussillon) según Tison \& Foucault (2014). Además, se analiza el estatus y la presencia histórica de C. floribunda Kunth, dentro del cual incluyo C. bilbaoana J. Rémy por los motivos manifestados en el texto correspondiente.

El trabajo está centrado en el NE de la Península Ibérica, principalmente en Cataluña, pero con referencia al ámbito de trabajo considerado en Bolòs \& Vigo (1984-2001), lo que incluye el departamento francés de los Pirineos Orientales y la Comunidad Valenciana. Aragón, región que el autor conoce bien, entra también en el territorio comprendido aquí.

La confusa taxonomía de Conyza pone de manifiesto la falta de consenso entre los distintos autores, por lo cual lo que se pretende aquí es comunicar una visión práctica para la discriminación de las entidades nomenclaturales de este género presentes en nuestro entorno. El número elevado 
de determinaciones incorrectas en los herbarios se podría reducir, o bien disminuyendo al mínimo el número de táxones reconocidos, o bien aportando una información más amplia y detallada. He optado por este último método y ofrezco una visión menos sintética que la de Morales (2019). Incluyo un apéndice al final de este trabajo que recoge la relación de pliegos estudiados de los táxones menos conocidos, además de una selección de fotografías.

\section{MATERIAL Y MÉTODOS}

Una visión práctica basada en observaciones hechas en el campo y en el herbario me lleva a reconocer cinco táxones presentes actualmente en el territorio, más dos que encontramos en los herbarios, de los cuales faltan recolecciones recientes. En cuanto a los híbridos putativos he señalado dos por el interés que tienen en la región.

Con estos siete táxones (cinco especies y dos variedades) he elaborado una clave dicotómica para acompañar las notas sobre cada uno de ellos. También recomiendo las claves y descripciones presentadas en Flore de la France méditerranéenne continentale, ut Erigeron (Tison et al., 2014), además de las fotografías de la fig. 122 en el libro británico Alien plants (Stace \& Crawley, 2015).

Los táxones reconocidos con testigo de herbario reciente son: $C$. bonariensis (L.) Cronq. var. bonariensis, $C$. canadensis var. canadensis, $C$. canadensis var. glabrata, $C$. floribunda y $C$. sumatrensis (Retz.) E. Walker. Los táxones de presencia histórica, sin referencias para Cataluña en los últimos 50 años o más, son $C$. bonariensis var. angustifolia (Cabrera) Cabrera (sin citas comprobadas desde 1969) y C. primulifolia (Lam.) Cuatrec. \& Lourteig (sin citas desde 1920). Un taxon polémico, $C$. daveauana Sennen, presente actualmente en la región, y un híbrido, C. ×mixta Fouc. \& Neyr., de relevancia para este estudio, reciben un tratamiento provisional en espera de un estudio más detallado. Para cada taxon incluyo los sinónimos más relevantes y una breve descripción tanto de las especies tratadas aquí como de las variedades.

Por lo que sabemos, como indican Urdampilleta et al. (2005), C. canadensis es diploide $(2 n=18)$, $C$. primulifolia es octoploide y los demás táxones son hexaploides, aunque no he podido encontrar datos para $C$. daveauana o los híbridos. Los detalles de los pliegos de herbario se encuentran en el apéndice, sin incluir los de las especies comunes y extendidas por gran parte de la Península.

La clave que ofrezco a continuación se ajusta a las poblaciones y al material de herbario centrado en Cataluña, aunque soy consciente de que las dimensiones y algún otro carácter morfológico pueden variar un poco en otras regiones del mundo. La inclusión de los dos táxones no encontrados en tiempos recientes tiene por finalidad ayudar a aclarar su situación en el caso de que se encontraran de nuevo en nuestro ámbito. Ambos siguen presentes en la actualidad en otras regiones de la Península. En el caso de que una planta no se resuelva con la clave, el lector encontrará información adicional en el apartado "Táxones conflictivos e híbridos".

\section{RESULTADOS}

\section{Clave de las especies}

1. Capítulos grandes (en la antesis, $c a .10 \times 15 \mathrm{~mm}$.). Receptáculo de \pm 7-8 mm; involucro de largo 6-8 $\mathrm{mm}$ con brácteas densas y cortamente pubescentes (blanquecinas); hojas oblanceoladas, crenato-lobuladas, distantes entre sí. 5. C. primulifolia.

-. Capítulos más pequeños; involucro más corto, de (3) 4-5(6) mm, con brácteas de pubescencia variable, o glabras; hojas de lineares a anchamente lanceoladas u ovadas, densa- a laxamente dispuestas.

\section{2}

2. Capítulos de 2-3 mm de diámetro; receptáculos (al fructificar) de 1,2-2,5 mm; lígulas de las flores externas 0,5-1,5 $\mathrm{mm}$; corola de las flores internas con 4 lóbulos (ocasionalmente cinco en la var. glabrata)

1. C. canadensis

-. Capítulos de (3)4-6 mm diámetro; receptáculos de los capítulos (al fructificar) de $2-4 \mathrm{~mm}$; lígulas menores; lóbulos de las corolas internas siempre cinco.

\section{3}

3. Capítulos muy numerosos; cara externa de las brácteas del capítulo glabra o con pocos pelos esparcidos por la zona mediana; hojas basales y medianas a menudo ciliadas en la zona proximal, las basales normalmente con lóbulos estrechos salientes.

4. C. floribunda

-. Capítulos numerosos o no; brácteas pubescentes en la cara externa; hojas con cortos pelos curvados en los márgenes 
4. Plantas de porte bajo (12)25-70(90) cm, verde-grisáceas, y de ramificación simpodial (excepto var. angustifolia); hojas estrechas, las basales oblanceoladas a lineares, irregularmente dentadas o enteras, las distales lineares; capítulos con brácteas internas a menudo purpúreas distalmente; brácteas estrechándose hacia la base; vilano blanquecino cuya anchura, expandida, es de 12-16 mm.

2. C. bonariensis

-. Plantas altas (hasta unos $200 \mathrm{~cm}$ ), verdes, ramificadas o no desde la base, con hojas basales lanceloladas a oblanceoladas (largas 10-12 cm como media normal; anchas $1-4 \mathrm{~cm}), \pm$ regularmente dentadas; inflorescencia densa, monopodial, piramidal, con un gran número de capítulos de brácteas nunca purpúreas distalmente; brácteas más anchas en el tercio basal; vilano de color paja en la fructificación cuya anchura, expandida, es de 8-12 mm

3. C. sumatrensis

\section{Perfil de los táxones comprendidos dentro del} marco de este trabajo

1. Conyza canadensis (L.) Cronq. in Bull. Torrey Bot. Club 70: 632 (1943)

$\equiv$ Erigeron canadensis L., Sp. P1.: 863 (1753)

Incluye var. canadensis y var. glabrata (A. Gray) Cronq.

En el territorio es posible reconocer dos variedades que se distinguen bien en la mayoría de los casos. De las muchas poblaciones y recolecciones observadas solamente unas pocas plantas han presentado cierta dificultad, la cual ha hecho más problemática su asignación a una u otra variedad. Floración: (julio) agosto-noviembre.

Clave de las variedades detectadas en el territorio:

1. Inflorescencia \pm cilíndrica; tallos y hojas hirsutas y ciliadas; corola de las flores internas tetrámera; receptáculo de 1,8-2,5 mm var. canadensis

-. Inflorescencia generalmente cónica; tallos y hojas glabrescentes (con cilios en los márgenes proximales de las hojas); corola de las flores internas tetra- o pentámera; receptáculo de 1,2$2 \mathrm{~mm}$
Var. canadensis: plantas hirsutas de mayor o menor medida, las hojas híspidas y ciliadas con cilios patentes en los bordes. Inflorescencia generalmente alargada y \pm cilíndrica $(5-15 \mathrm{~cm}$ de anchura total); brácteas medias e internas del involucro de $\pm 0,5$ $\mathrm{mm}$, la punta sin mancha purpúrea. Corola de las flores internas (hermafroditas) con 4 lóbulos. Distribuida por gran parte del territorio, siendo más frecuente en las tierras del interior (especialmente en el pre-Pirineo y los valles del Pirineo tanto en Aragón como Cataluña por debajo de $1500 \mathrm{~m}$ de altitud, excepcionalmente hasta $1700 \mathrm{~m}$ ). Hay indicios de que este taxon está en regresión, incluso en el norte de Europa (Rand, 2008).

Var. glabrata: plantas con tallos y hojas glabras o glabrescentes, las hojas ciliadas en los bordes con cilios adpresos, pero patentes en la zona proximal. Inflorescencia habitualmente ampliamente cónica $(10-30 \mathrm{~cm}$ de anchura total); brácteas medias e internas del involucro estrechas $(0,3-0,4 \mathrm{~mm})$, la punta a menudo con una pequeña zona de color púrpura. Corola de las flores internas con 4 o 5 lóbulos. Distribuida por las tierras bajas del territorio, hasta $560 \mathrm{~m}$. En expansión por el territorio.

Al tratarse de una variedad no detallada en las floras de la región, y la primera identificación de este taxon a escala europea, a continuación añado una descripción y más detalles sobre su distribución e historia.

Conyza canadensis (L.) Cronq. var. glabrata (A. Gray) Cronq. in Bull. Torrey Bot. Club 74(2): 150 (1947)

$\equiv$ Erigeron canadensis var. glabratus A. Gray in Boston J. Nat. Hist. 6: 220 (1850)

=E. strictus DC., Prodr. [A. P. de Candolle] 5: 289 (1836)

$=$ E. canadensis var. levis Makino in J. Jap. Bot. 3(7): 26 (1926)

Se trata de una planta probablemente introducida durante el siglo XX, que ha causado algún que otro problema a la hora de interpretarla. En los herbarios y trabajos florísticos del país ha sido recogida o sensu lato, bajo el nombre de C. canadensis $\sin$ referencia al nivel infraespecífico, o dentro de $C$. blakei, especie que se creía presente en la Península Ibérica, pero actualmente queda provisionalmente descartada, y cuyas citas en su mayoría corresponden a $C$. floribunda. Aquí propongo la aplicación de este nombre varietal, rango que considero el más 

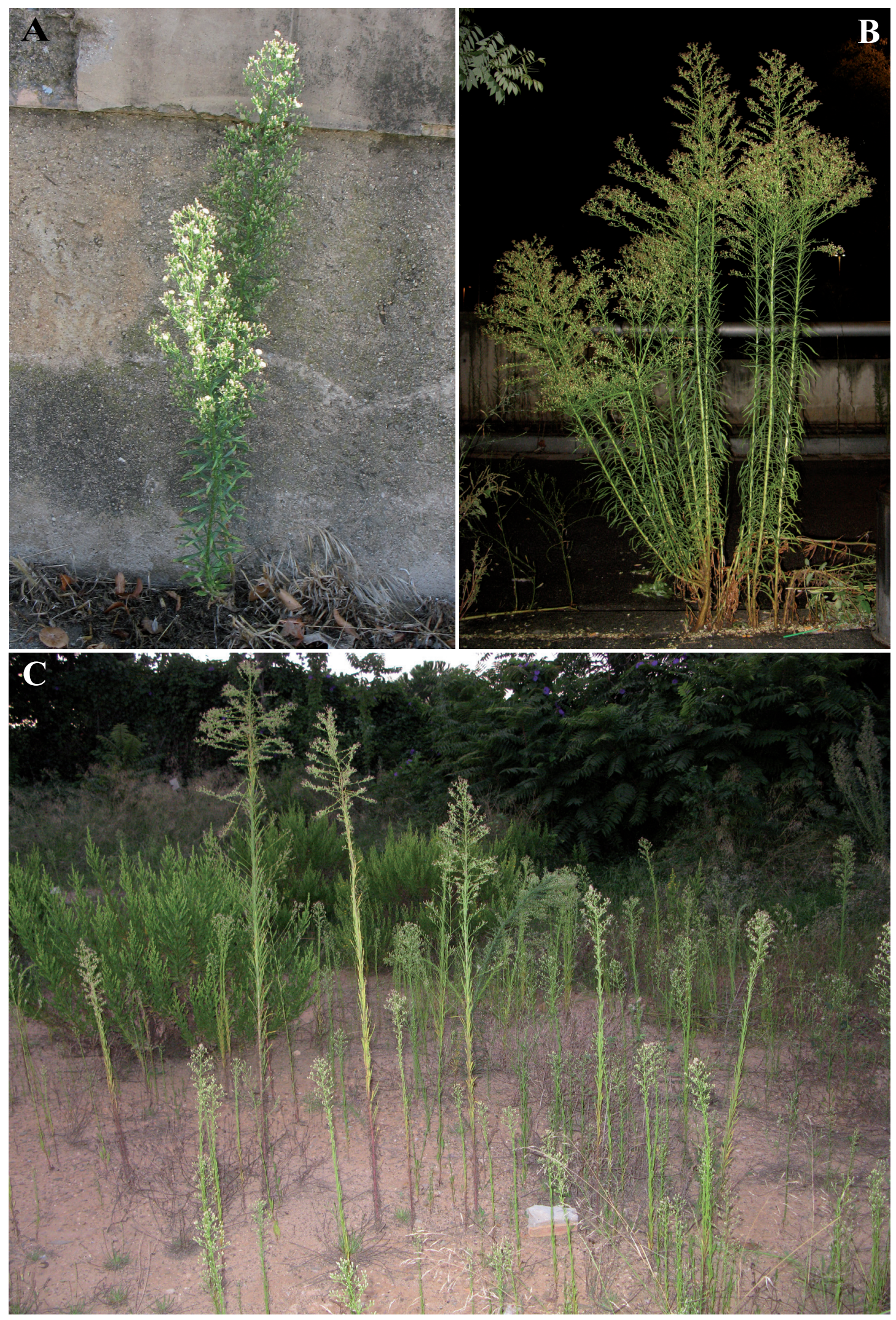

Figura 1. (A), Conyza canadensis var. canadensis en Manlleu (Osona) a finales de agosto, 2019. En esta localidad coinciden ambas variedades; (B), Conyza canadensis var. glabrata invade las calles de Barcelona. Unas plantas de casi $2 \mathrm{~m}$ de altura cerca de la Plaça de Cerdà; (C) Conyza canadensis var. glabrata en el solar de Antoni Julià de Capmany, Montjuïc, Barcelona (fotografias: S. Pyke). 
apropiado para el necesario reconocimiento de esta zamarraga en vías de expansión por el Mediterráneo.

Asa Gray, uno de los más respetados botánicos americanos del siglo XIX, estudió en detalle las recolecciones de Berlandier y Lindheimer hechas en Texas, EEUU, y dio un nombre nuevo a las de una morfología distinta, mientras llevaba otras a la especie típica (var. canadensis, para nosotros). Entre las plantas estudiadas se entiende que pudo observar el "Erigeron strictum" (ahora E. strictus) de Augustin de Candolle, una planta referible a C. canadensis sensu lato, y de la cual comentó que no estaba de acuerdo con su estatus de especie. Al describir su taxon, Gray se refirió a $E$. strictus DC., pero añadió: sed panicula composita expansa. Estas poblaciones de las descripciones originales se encuentran en el sur de Texas: "prairies north of the Liano, among granite rocks" se lee en la etiqueta del lectótipo. Erigeron strictus pasaría, pues, a la sinonimia de esta variedad de $C$. $c a$ nadensis, donde la coloca Gray. De hecho, E. strictus representa una forma poco frecuente, algo aberrante, con las ramas de la inflorescencia reducidas. He observado casos extremos de este fenómeno en otras especies del género. De nuevo, no conviene tener en cuenta un solo carácter sino el conjunto de caracteres.

En cuanto a nuestra var. glabrata, se trata de una planta capaz de formar grandes poblaciones en terrenos alterados algo húmedos. Es una planta alta que a menudo sobrepasa $1 \mathrm{~m}$ de altura (he observado plantas de hasta $2 \mathrm{~m}$ ), pero en suelos ralos se pueden encontrar ejemplares depauperados de menor tamaño. $\mathrm{Al}$ igual que $C$. canadensis var. canadensis, no suele ramificarse. Las inflorescencias, no obstante, son muy ramificadas y típicamente anchamente cónicas, con ramificaciones patentes, de entre $45^{\circ}$ a $90^{\circ}$. Los tallos largos, casi glabros, están provistos de muchas hojas sublineares y enteras, densamente dispuestas. Las hojas basales son más o menos dentadas, aunque a menudo enteras. Todas las hojas son subglabras, con cilios aplicados en los márgenes hasta la punta distal, pero con pelos patentes solamente en la zona basal. Los capítulos, aunque ligeramente más pequeños, son muy semejantes a los de la variedad típica, con las brácteas medias del involucro con unos pocos pelos esparcidos o a veces glabras. Con aumento de $10 \times$ se aprecia, en muchas plantas, un color violetamorado en la punta misma de la bráctea, lo cual apenas se aprecia en el material de herbario. Este detalle se suele asociar con el involucro de $C$. canadensis var. pusilla (Nutt.) Cronq., pero no parece constituir un carácter determinante (Britton, 1914). Las lígulas de las flores externas son muy cortas, y puede que no se aprecien en seco.

Erigeron canadensis var. levis Makino, de Japón, carece de material tipo, pero muy probablemente debe incluirse dentro de la sinonimia de la var. glabrata en vez de la de var. pusilla, a la que pertenecía según Tuyama \& Asai (1967). Las poblaciones asiáticas, como reconocían estos autores, son plantas altas con panículas bien desarrolladas que contienen un número muy elevado de capítulos, caracteres que corresponden a la var. glabrata. Estas se conocen del sur de Japón, Taiwán y otras islas del Pacífico.

Distribución en Cataluña: comarcas de la costa desde la frontera francesa hasta el Baix Camp, más la Plana de Vic y alguna comarca más del interior. Está presente, por tanto, en las provincias de Girona, Barcelona y Tarragona. Llega más al sur, como confirma un pliego de Corbera de Alcira (hoy, Corbera) en la Ribera Baixa de Valencia. Se puede proyectar su expansión hacia el sur, y hacia el Bajo Aragón, aprovechando las vías de comunicación. Hasta la fecha de esta publicación no la he observado en Aragón. Saber más de su distribución al nivel continental requiere, en primer lugar, reconocerla, y luego, revisar el material disponible. Parece mostrar una preferencia por los suelos silíceos o neutros. Florece habitualmente entre septiembre y noviembre aunque, según el año, puede ser más precoz, empezando hacia finales de julio.

2. Conyza bonariensis (L.) Cronq. in Bull. Torrey Bot. Club 70: 632 (1943)

$\equiv$ Erigeron bonariensis L., Sp. P1.: 863 (1753)

$=$ E. crispus Pourr. in Mem. Acad. Toulouse 3: 318 (1788)

$=$ E. linifolius Willd., Sp. Pl. 3: 1955 (1803)

= Conyza ambigua DC. in Lam. \& DC., Fl. Franç., ed. 3. 6: 468 (1815)

Incluye var. bonariensis y var. angustifolia (Cabrera) Cabrera

Esta zamarraga es una de las más extendidas por las tierras mediterráneas, y en las zonas más secas y cálidas es la única especie que encontramos. Resulta muy frecuente en el entorno urbano, donde se adapta perfectamente a las condiciones impuestas por el hombre. Cabrera (1974) divide las poblaciones de Argentina en tres variedades, dos de las cuales 
permanecen en la circunscripción de la especie generalmente aceptada hoy en día: var. bonariensis y var. angustifolia (Cabrera) Cabrera. Su var. microcephala (Cabrera) Cabrera parece corresponder a $C$. sumatrensis (Pruski \& Sancho, 2006; Nesom, 2018).

Podemos confirmar la presencia de la var. bonariensis [siguiendo la lectotipificación de D'Arcy (1975)] en la Península Ibérica. La var. angustifolia, mucho menos frecuente, requiere más estudio antes de poder concretar su distribución en el territorio y en el sur de Europa. Su presencia podría ser histórica dentro de Cataluña, ya que faltan recolecciones recientes, aunque en el conjunto de la Península Ibérica hay testigos más recientes.
Clave de las variedades detectadas en el territorio:

1. Planta simple o ramificada; inflorescencia con crecimiento simpodial, sus ramas inferiores largas, a menudo pasando el eje central; hojas variables, las proximales de (3)5-9(12) mm de ancho, generalmente con dientes o lóbulos. var. bonariensis

-. Planta simple o con varios tallos fértiles que parten de la mitad inferior; inflorescencia en estos tallos \pm cilíndrica, los capítulos generalmente dispuestos en panojas alargadas (con ramificación corta); todas las hojas estrechamente lineares, de 1-2(3) mm, generalmente sin dientes o lóbulos.
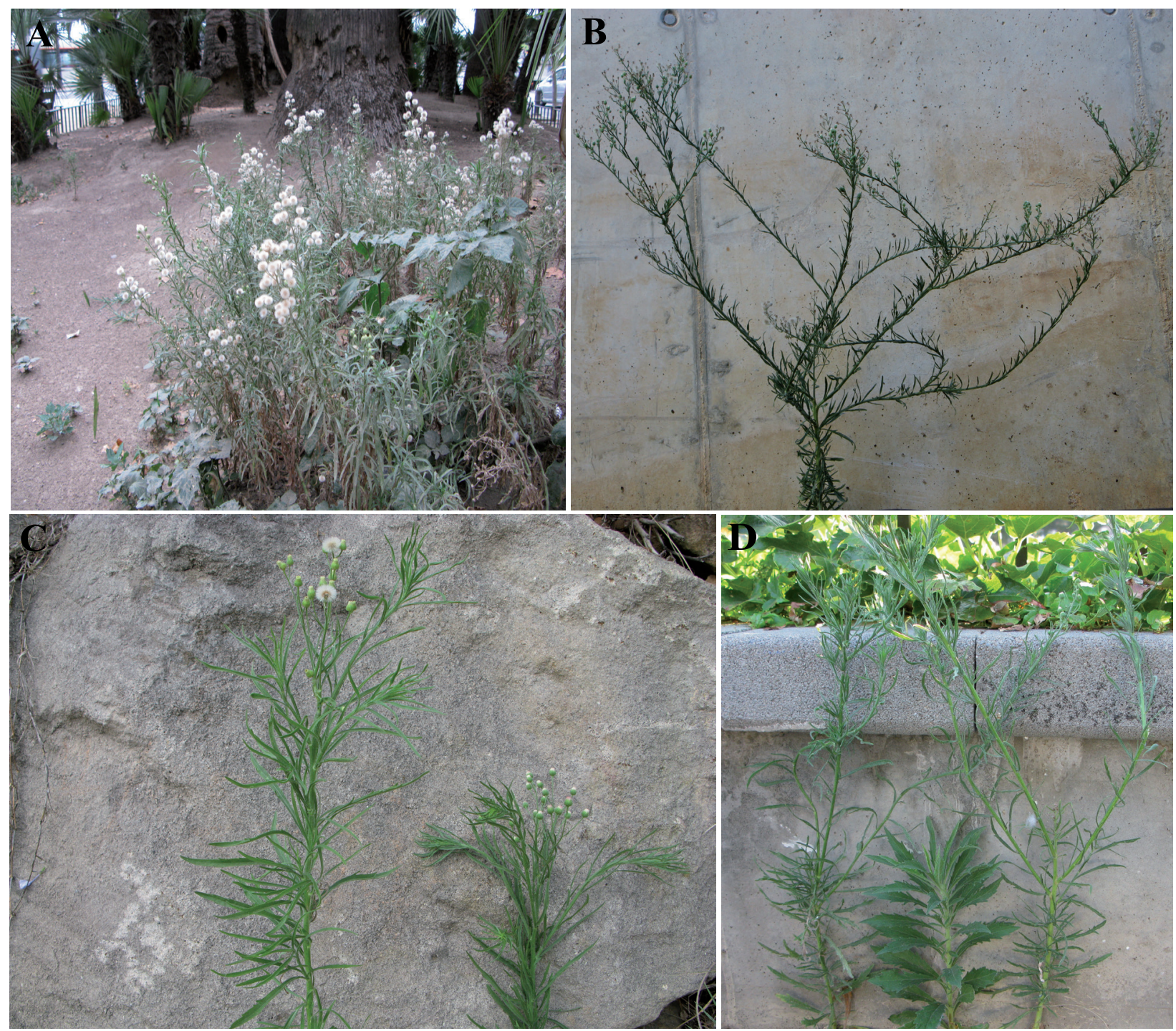

Figura 2. (A), Conyza bonariensis var. bonariensis a principios de julio, 2019, en la Plaça del Duc de Medinaceli, Barcelona; (B), Conyza bonariensis var. bonariensis, mostrando ramificación simpodial. Septiembre 2019; (C), Conyza bonariensis var. bonariensis. Plantas jóvenes. Montjuïc, principios de julio, 2019, (D), Conyza sumatrensis escoltada por C. bonariensis var. bonariensis a principios de julio, 2019 (fotografías: S. Pyke). 


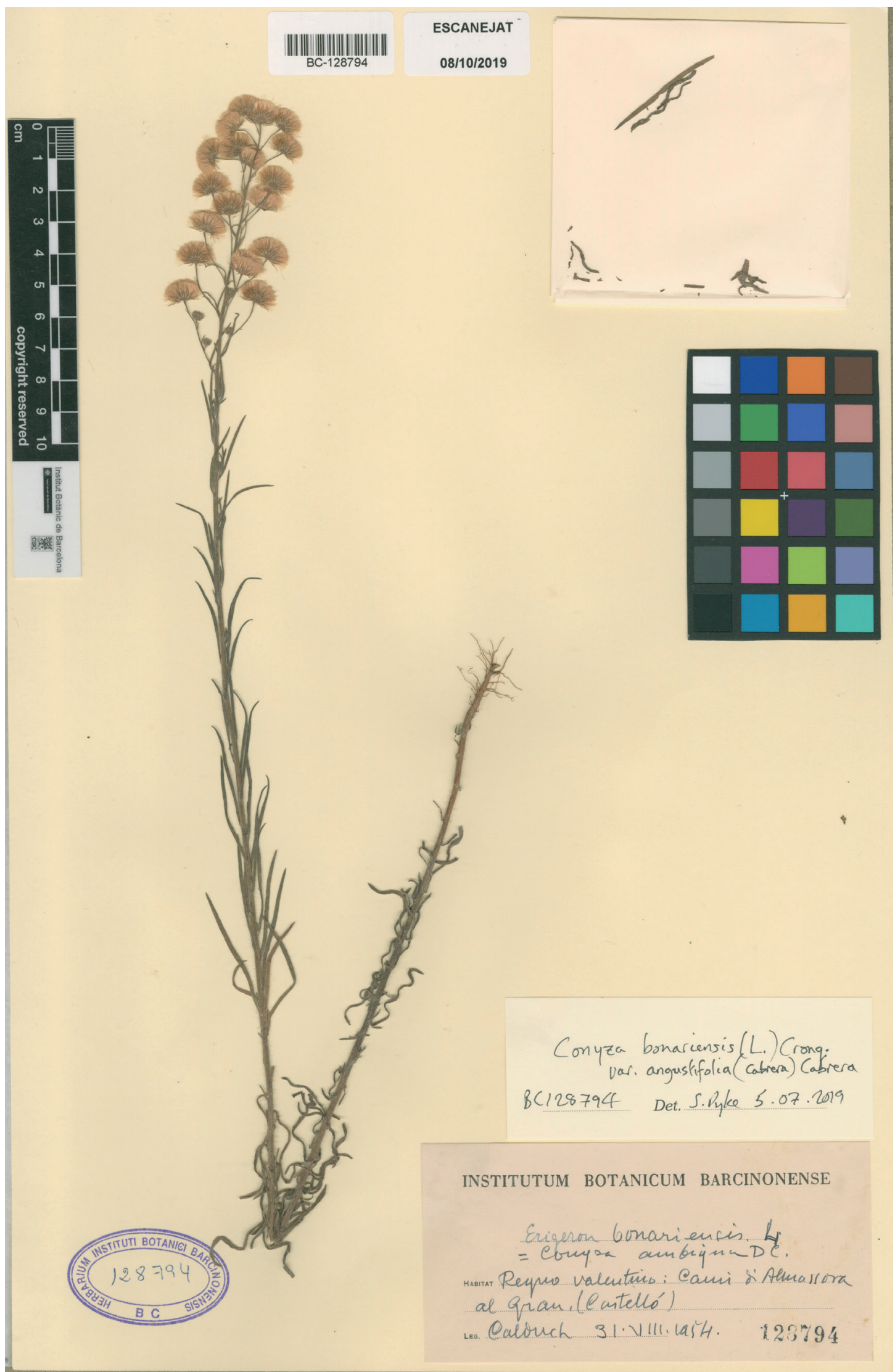

Figura 3. Pliego de Castellón de la Plana atribuible a Conyza bonariensis var. angustifolia del año 1954. 
Var. bonariensis: Se distingue por ser una planta de porte modesto, con tallos de (12)25-70(90) cm, densamente pubescente (con pelos aplicados y otros más largos y patentes), hojas estrechas y lineares, normalmente un poco onduladas, las basales irregularmente dentadas, normalmente más anchas, las de media talla también dentadas y las superiores \pm enteras. Inflorescencias sub-corimbosas, las ramas inferiores largas y a menudo sobrepasando las superiores. Capítulos con brácteas uniformemente pubescentes. Comienza la floración en mayo o junio, según el año, haciéndose más llamativa con la fructificación, la cual normalmente empieza en junio y sigue durante los meses de verano y otoño. Ampliamente distribuida por la región. Asciende a aproximadamente $1200 \mathrm{~m}$.

Var. angustifolia (Cabrera) Cabrera: Es semejante a la var. bonariensis, y se la puede distinguir principalmente por tener todas sus hojas estrechas, de 1-2(3) mm de anchura. Según Cabrera, tiene un indumento más corto, dándole un aspecto ceniciento. Su porte bajo (alcanza unos $30 \mathrm{~cm}$ ), más la estructura de la inflorescencia, la otorgan un aspecto un tanto distinto (véase la clave). Plantas de la variedad típica con hojas estrechas han sido interpretadas en ocasiones con este nombre. Conviene observar bien la población y coger ejemplares representativos con el fin de evitar una muestra de plantas pequeñas que no representan bien los caracteres del taxon. Algunos pliegos de herbario que corresponden en sus caracteres morfológicos al parátipo LP006952 (Leg. Salellas, 1929), verificado por Cabrera, apuntan a la presencia de la var. angustifolia en la región antes del año 1970 (véase apéndice). Es una variedad poca recolectada; los pliegos son de las tierras costeras.

Una planta de más altura, el híbrido $C$. $\times$ mixta Fouc. \& Neyr. (=C. $\times$ flahaultiana Sennen $)$ muestra un cierto parecido a este taxon (véase el apartado "Táxones conflictivos e híbridos").

El aspecto más grisáceo, la floración más temprana, su porte más bajo, la estructura de la inflorescencia, el color de las brácteas, y las cabezuelas fructificadas más grandes y más blanquecinas (en estado fresco), sirven para diferenciar estos dos táxones de $C$. sumatrensis y $C$. floribunda.

3. Conyza sumatrensis (Retz.) E. Walker in J. Jap. Bot. 46: 72 (1971) $\equiv$ Erigeron sumatrensis Retz., Observ. Bot. 5: 28 (1788)

= Conyza altissima Naudin ex Debeaux in Soc. Agric. Sci. Litt. Pyrénées-Orientales 23: 151 (1878) $=C$. naudinii Bonnet in Bull. Soc. Bot. France 25: 208 (1878)

$=C$. bonariensis var. microcephala (Cabrera) Cabrera, Man. Fl. Alrededores Buenos Aires: 481 (1953)

=C. floribunda var. subleiotheca (Cuatrec.) J. B. Marshall in Watsonia 9: 372 (1973)

- C. ambigua auct. pl. non DC.

Aunque existen algunos testigos antiguos en los herbarios, bajo el nombre de C. naudinii, y también $C$. ambigua en algunos casos (nombre aplicado correctamente y con más frecuencia a $C$. bonariensis), esta especie se habría introducido en Europa en tiempos posteriores a la introducción de C. bonariensis. Sennen (1904) ya habla de ella (ut $C$. naudinii) referiéndose a algunas poblaciones abundantes entre Le Boulou y l'Empordà. Casasayas (1989) explica que estaba presente en el sur de Francia en el año 1875. De acuerdo con esta autora, se constata que la especie ha aumentado de una manera significativa su presencia en la Península Ibérica en los últimos 100 años.

Las plantas nuestras son altas, (40)80-120(220) $\mathrm{cm}$, y bastante uniformes, excepto en cuanto a la anchura y los márgenes de las hojas, éstas muy variables, y el contorno de la panícula. Las hojas basales, de (0,8)1-3(4) cm de anchura, son lanceoladas o oblanceoladas, la lámina largamente decurrente en el pecíolo, regularmente dentada con dientes gruesos. Las hojas del tallo se reducen en tamaño, dentadas, pero de menor medida, hacia la inflorescencia. El color general de nuestras plantas es algo más verde que en $C$. bonariensis. La inflorescencia consiste en una panícula normalmente piramidal, pero estrechándose hasta llegar a ser casi cilíndrica en algunas poblaciones, con muchos capítulos, las ramas inferiores no especialmente largas. En la fructificación, los capítulos son más pequeños que en $C$. bonariensis, y el vilano es de un color amarillento o de paja en estado fresco, tendiendo a oscurecerse en el herbario. Toda la planta es hirsuta o pubescente, incluso las brácteas del involucro, las internas lanceoladas, $c a .5 \mathrm{~mm} \times 1 \mathrm{~mm}$ en nuestras plantas. Se puede consultar Qureshi \& Raana (2013) para una descripción más completa. 

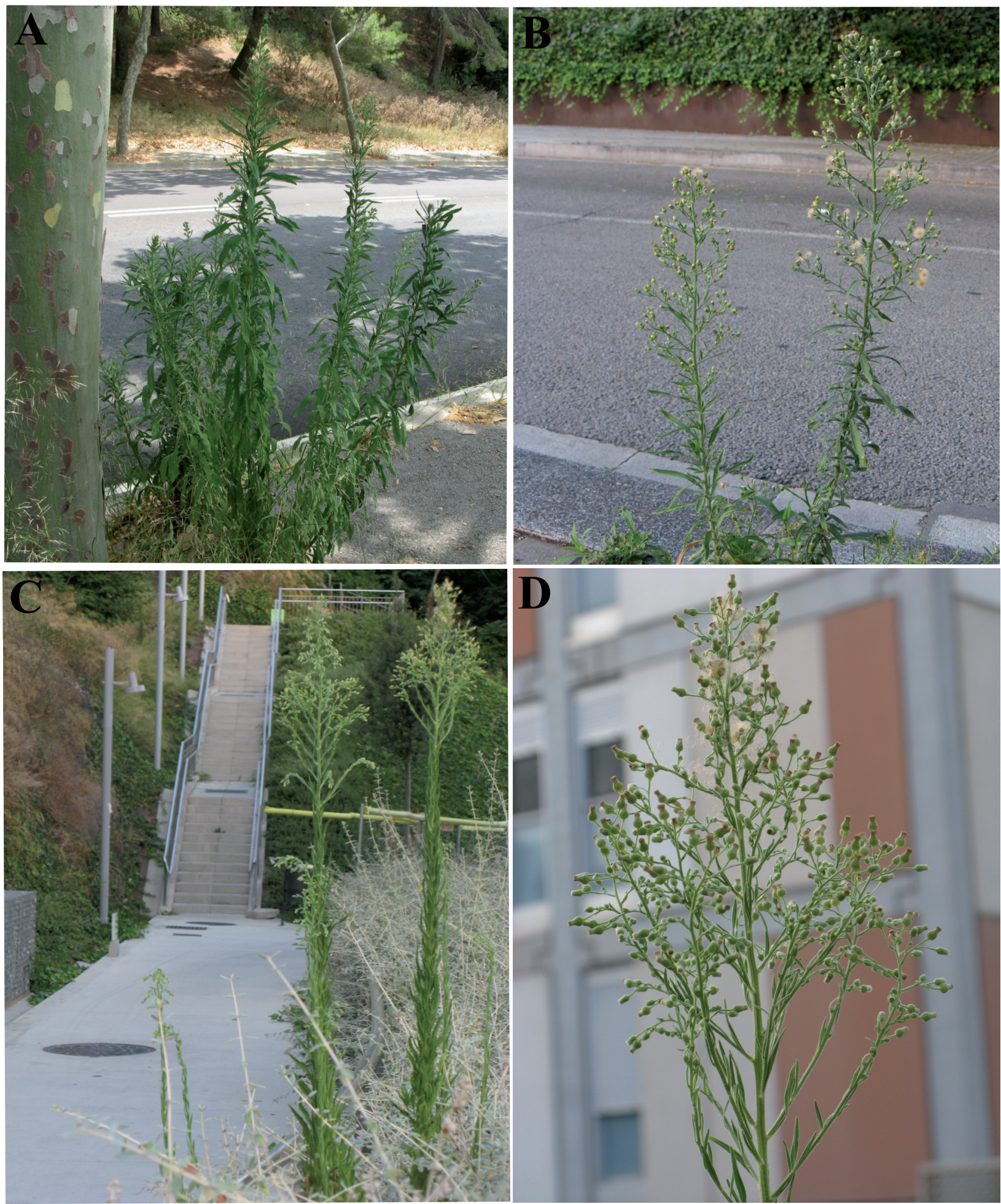

Figura 4. (A), Conyza sumatrensis en julio, 2019. Las hojas basales en este ejemplar miden $30 \mathrm{~mm}$ de anchura; (B), Conyza sumatrensis. Plantas de reducido tamaño con hojas basales estrechas, menos dentadas de lo normal, son frecuentes; (C), Conyza sumatrensis. Planta de $2 \mathrm{~m}$ altura. Como indica uno de sus sinónimos, C. altissima, los especímenes altos son habituales; (D), Conyza sumatrensis en septiembre 2019. Es una planta variable, pero la imagen muestra el contorno más típico de la inflorescencia (fotografías: S. Pyke). 
En cuanto a la sinonimia, no obstante la interpretación de Nesom (2018: 12), el holótipo de $C$. ambigua DC. (P03681968) representa no C. sumatrensis sino $C$. bonariensis. Aquí estoy de acuerdo con la conclusión de Zardini en su nota dentro del pliego, el cual habrá estudiado personalmente. El tipo del sinónimo de Cuatrecasas " $C$. bonariensis var. leiotheca f. subleiotheca Cuatrec." es del departamento de Boyacá, Colombia, recolectado en 1938 (Cuatrecasas, 1969). El epíteto albida Willd. ex Spreng. ha sido aplicado a esta especie, pero según Nesom (2018) el material tipo de C. albida (de Brasil) claramente pertenece a C. floribunda. Aún existen discrepancias referentes a la aplicación correcta del nombre de Willdenow, tal vez, entre otras cosas, porque el epíteto albida parece poco apropiado.

Mi concepto de $C$. sumatrensis se ajusta satisfactoriamente a la descripción original de Retzius basada en una planta recolectada por un tal reverendo Wennerberg, ut "Erigeron sumatrense", del este de Sumatra. La descripción indica calyx tomentosus, detalle que corresponde a las plantas de nuestro concepto. En ausencia del material original, McClintock \& Marshall establecieron un neótipo, de Berastagi, Sumatra. El problema es que el material del neótipo corresponde, más bien, a C. floribunda; entre otros detalles, por sus brácteas glabrescentes. Las dudas en cuanto a la tipificación de la planta que Retzius describió han llevado algunos autores a unir estos dos táxones. No obstante, se distinguen bien en Europa, y estoy a favor de seguir usando el nombre de Retzius para la planta del involucro pubescente hasta que se resuelvan las dudas.

Conyza sumatrensis es una especie común, de amplia distribución en nuestra región. Asciende hasta los $1000 \mathrm{~m}$ de altitud. Florece a partir de julio. Es probable que tenga su origen en el norte del continente sudamericano (Brasil, las Guayanas, Venezuela, Colombia y otros países colindantes) aunque hoy día se distribuye por gran parte de las regiones de clima tropical y templado del mundo.

4. Conyza floribunda Kunth in Humboldt \& al., Nov. Gen. Sp. 4, ed. f: 57 (1818)

$\equiv$ Erigeron floribundus (Kunth) Sch. Bip. in Bull. Soc. Bot. France 12: 81 (1865)

= Conyza albida Willd. ex Spreng., Syst. Veg. 3: $514(1826)$
= Conyza bilbaoana Rémy in Gay, Fl. Chil. 4: 76 (1849) $\equiv$ Erigeron bilbaoanus (Rémy) Cabrera in Revista Mus. La Plata, Secc. Bot. 4: 254 (1941)

$=$ Erigeron coronopifolius Sennen in Bull. Soc. Bot. France 68: 406 (1922)

$=$ E. $\times$ gonzaloi Sennen in Bol. Soc. Ibér. Ci. Nat. 28: 66 (1929)

= Conyza bonariensis var. leiotheca (S. F. Blake) Cuatrec. in Phytologia 9: 5 (1963) $\equiv$ C. sumatrensis var. leiotheca (S. F. Blake) Pruski \& G. Sancho in Novon 16: 98 (2006)

Aunque algunos prefieren amalgamar esta especie con C. sumatrensis, hay criterios suficientes como para reconocer los dos táxones de forma independiente, ya sea como dos especies distintas o a un rango inferior que el de especie. Marshall (1974) juntó los dos táxones al nivel varietal dentro de C. sumatrensis (Retz.) E. Walker [var. floribun$d a$ (Kunth) J. B. Marshall], pero Stace (2010) y Nesom (2018), ut Erigeron, las tratan con el rango de especie.

Es una planta normalmente anual, pero puede perennizar, o al menos perdurar un segundo año. He recolectado muestras con base leñosa, de donde salen nuevas rosetas durante el invierno, lo que apoya las conclusiones de Thébaud \& Abbott (1995): "both $C$. blakei and $C$. floribunda exhibit a striking ability to shift from semelparous to iteroparous reproduction". Estos autores defienden que, en este sentido, se aproxima más a $C$. blakei que a $C$. sumatrensis.

Es de tamaño bastante elevado, de 50 a 150 (hasta 210$) \mathrm{cm}$ de altura, las plantas son típicamente ramificadas y de tallos laxamente hirsutos, las hojas ciliadas hacia la base, las basales con frecuencia lobuladas con lóbulos largos y delgados que salen de modo más patente que los de C. sumatrensis, las medianas dentadas o lobuladas y las superiores enteras. Posee una inflorescencia de contorno variable, bastante ancha, con un gran número de capítulos bastante pequeños, el involucro $\pm 4 \times 4$ $\mathrm{mm}$, glabro o casi glabro. Las plantas con capítulos muy pequeños, denominadas Erigeron $\times$ gonzaloi por Sennen, puede que constituyan el híbrido $C$. canadensis $\times C$. floribunda, aunque con reservas, debido a la gran variabilidad de $C$. floribunda.

Conyza floribunda es oriunda de América del Sur, presente desde Argentina y Chile hasta Colombia, principalmente por el corredor andino, y llega a otros países caribeños. El tipo es de Quito, 
Ecuador, recolectado por Humboldt y Bonpland. Aunque Pruski \& Sancho (2006) limitaron este taxon a los neotrópicos, Nesom (2018) y varios botánicos europeos (Tison \& Foucault, 2014; González-Martínez, 2015; Verloove, 2016) confirman la naturalización de esta planta tanto en EE.UU. como en Europa.

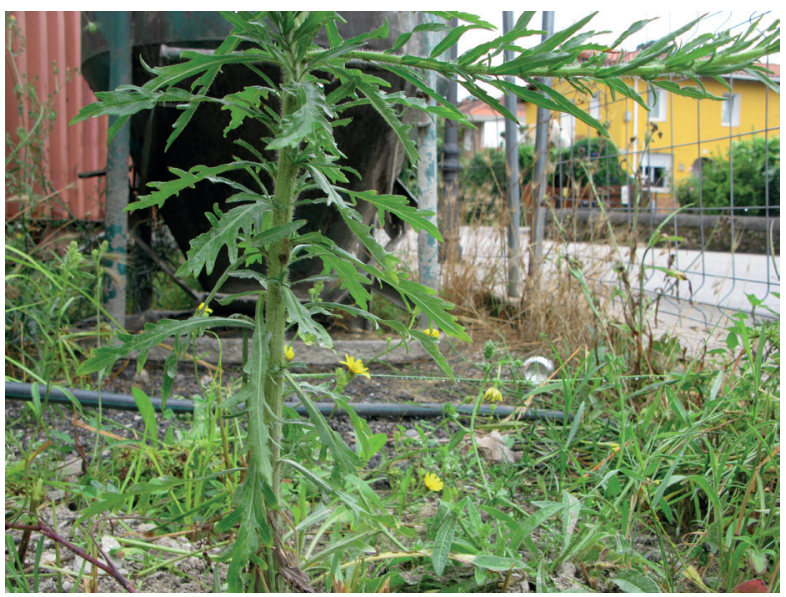

Figura 5. Conyza floribunda en un solar de la costa cantábrica, julio 2019, donde se aprecian las hojas basales y el característico indumento de los tallos (fotografías: S. Pyke).

Los pliegos en BC son del siglo pasado, de 1910 a 1998, algunos determinados por el mismo Sennen ut Erigeron coronopifolius (que no se debe confundir con Conyza coronopifolia Kunth, planta distribuida entre México y Perú/Bolivia, actualmente Erigeron variifolius $\mathrm{S}$. F. Blake, ni tampoco con $E$. coronopifolius Schrank, nombre con prioridad al ser de una publicación de Baviera de 1822, identificable con una planta sudafricana del género $\mathrm{Ni}$ dorella Cass.). La mayoría de estos pliegos son de la provincia de Barcelona (alrededores de Barcelona, el Maresme y la Plana de Vic). Algunos pliegos fueron denominados Conyza blakei (Cabrera) Cabrera, siguiendo un comentario de Thellung citado en Bolòs (1950), quien relacionaba E. coronopifolius con E. montevidensis Baker, un sinónimo de $C$. blakei. Como consecuencia, se introdujo esta idea en obras posteriores como Malagarriga (1965), Casasayas (1989) o Bolòs \& Vigo (1996). En esta última obra, ciertos detalles de la descripción ("ramificada únicament a la inflorescència" y "panícula cònica") corresponden, más bien, a $C$. canadensis var. glabrata.

Actualmente hay poca información sobre su presencia en la región, pero está documentada del sudoeste de Francia y del País Vasco ut C. bilbaoana J. Rémy (Verloove \& Sánchez Gullón, 2008). Dicho nombre ha sido considerado especie independiente, descrita de Chile, pero la evidencia hoy día apunta a su estatus como sinónimo de C. floribunda, éste teniendo prioridad. Refiriéndose a esta planta, Verloove (2016) comenta: "a common weedy species in the Spanish-French border area". Según el comentario que leemos en su blog, esta planta recuerda más a Erigeron canadensis que a E. sumatrensis o E. bonariensis (pero recordemos que $C$. floribunda tiene la corola pentámera). Mis propias observaciones de plantas vivas, basadas en poblaciones de Cantabria (ya que no he visto la especie en Cataluña), apoyan a Verloove en cuanto a la inflorescencia, pero el conjunto de las hojas me recuerda más a $C$. sumatrensis. Además de las brácteas, las hojas basales con sus largos lóbulos, cuando presentes, sirven para diferenciarla de esta especie. Las hojas basales de muchas plantas cántabras tienen mayor anchura (hasta $35 \mathrm{~mm}$, lóbulos incluidos) que las muy pocas presentes en el material tipo de $C$. bilbaoana que he podido estudiar telemáticamente. González-Martínez (2015) cita esta planta (ut C. bilbaoana J. Rémy) en su trabajo centrado en la provincia de A Coruña, Galicia. Le sorprende la falta de citas y material de herbario. Menciona también su presencia en Cantabria y otras partes del norte peninsular, además del sudoeste de Francia.

La entrada en la flora del País Vasco ut C. albida Willd. ex Spreng. (Aizpuru et al., 1999) probablemente se refiere tanto a esta planta (valles atlánticos, especialmente) como a C. sumatrensis. En Cantabria he visto plantas que interpreto como el híbrido $C$. floribunda $\times C$. sumatrensis, hecho que no debe sorprender, ya que ambas especies se encuentran en la misma región. Este híbrido putativo evidentemente complica nuestra percepción de las dos especies, y puede que haya contribuido a la confusión en torno a la aplicación del binomen $C$. albida.

A finales de agosto, 2019, en una prospección llevada a cabo en Manlleu y La Plana de Vic (Barcelona) con el fin de localizar C. floribunda (recolectada allí en 1923 por Hno. Gonzalo, ut Erigeron coronopifolius) pude observar cuatro zamarragas: C. bonariensis, C. canadensis var. canadensis, $C$. canadensis var. glabrata y $C$. sumatrensis. Las dos últimas están en franca expansión, juntamente con Symphyotrichum squamatum, muy abundante en los 


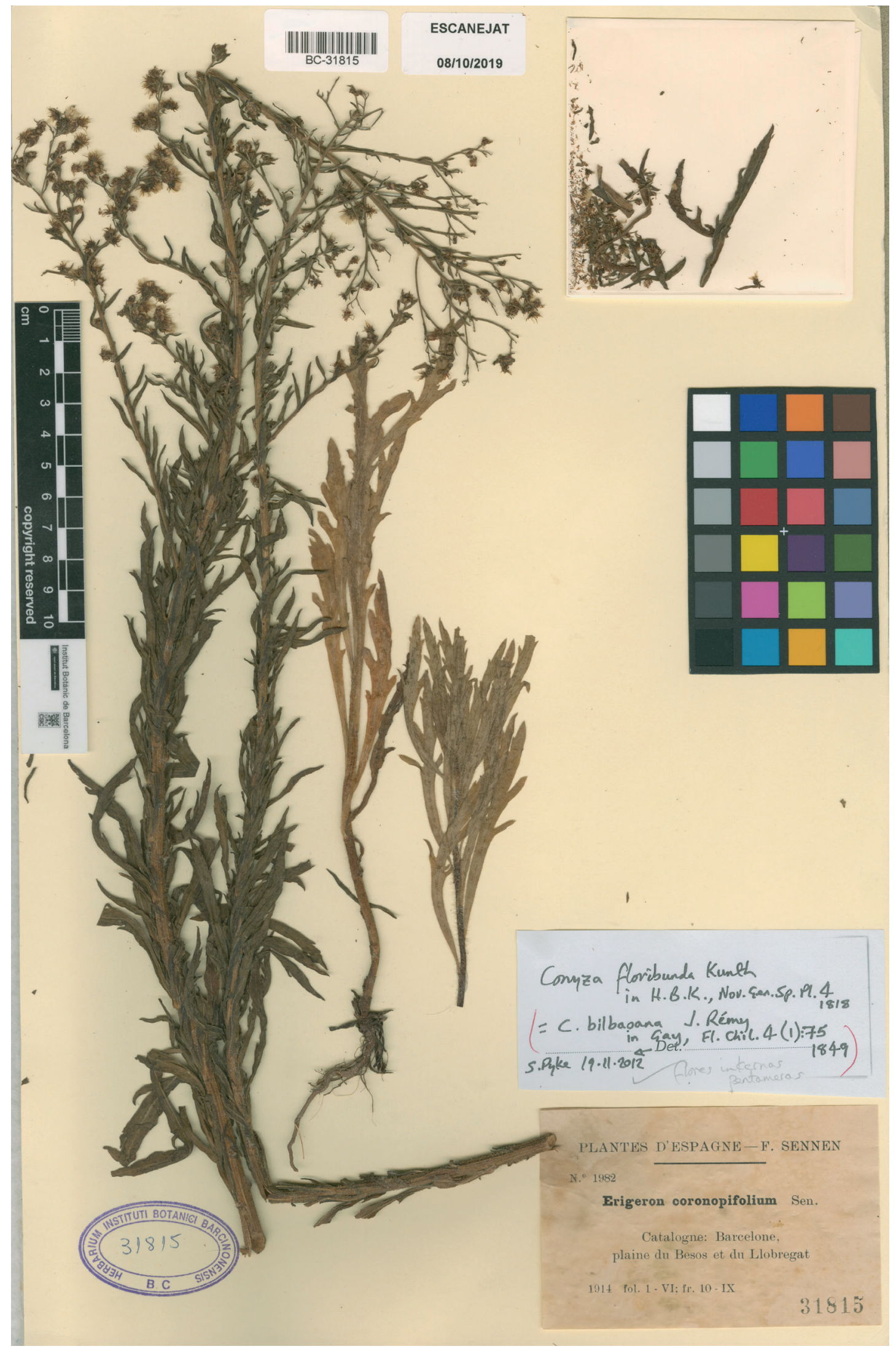

Figura 6. Pliego de herbario de Sennen, que confirma la presencia de Conyza floribunda en Cataluña a principios del siglo XX (ut Erigeron coronopifolius). 


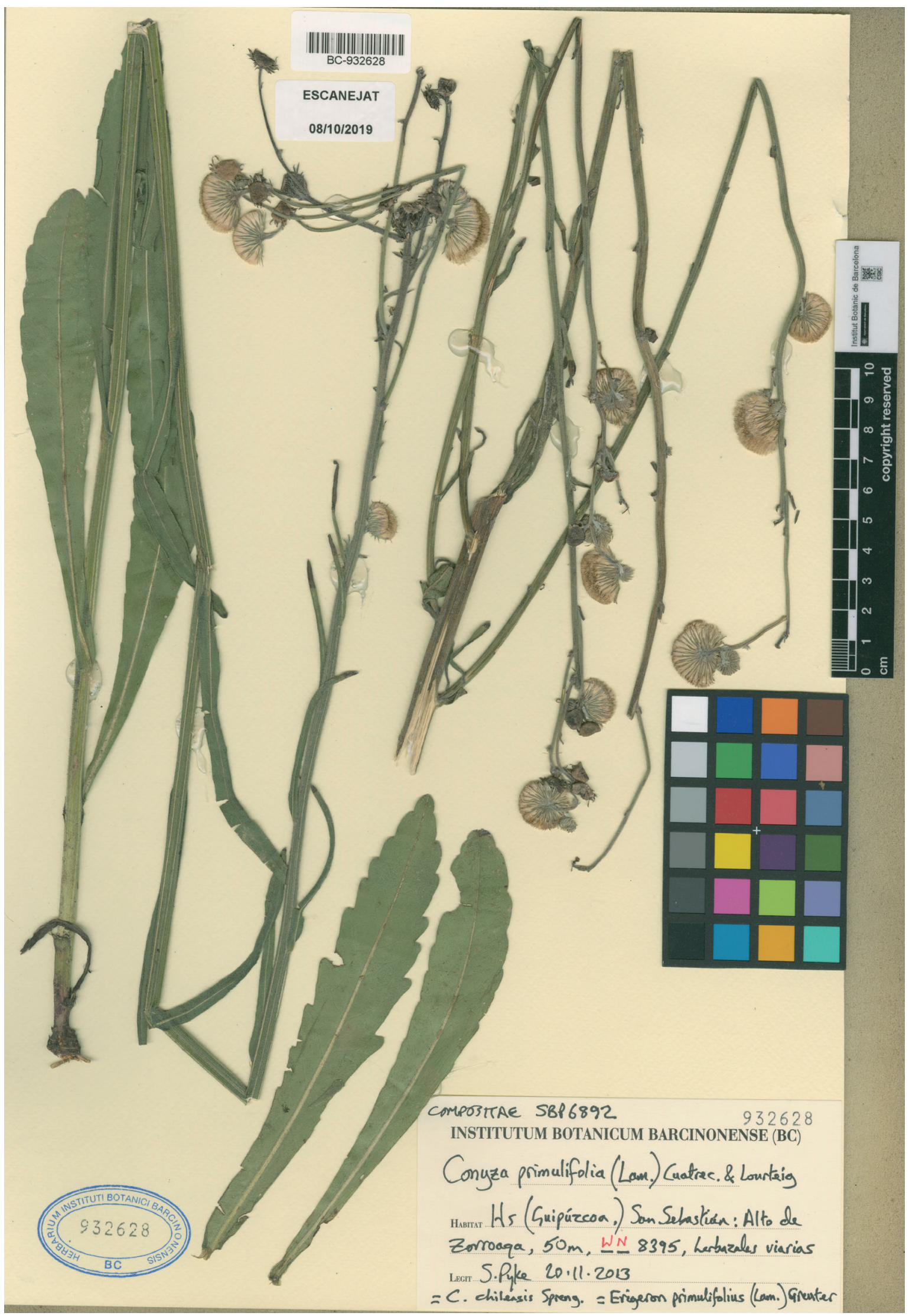

Figura 7. Conyza primulifolia. Muestra recolectada por el autor en el País Vasco en noviembre, 2013. 
mismos parajes. La evidente regresión de C. floribunda en Cataluña nos sugiere su dificultad a la hora de competir con otras invasoras. Si persiste en Cataluña, debe ser planta rara hoy día. Agradeceríamos cualquier dato reciente sobre su presencia y distribución en el territorio. Florece en el otoño, aunque las plantas que logran perennizar podemos encontrar con flores a partir de la segunda mitad de mayo.

5. Conyza primulifolia (Lam.) Cuatrec. \& Lourteig in Phytologia 58: 515 (1985)

三Inula primulifolia Lam., Encycl. 3: 261 (1789)

$\equiv$ Erigeron primulifolius (Lam.) Greuter in Willdenowia 33: 46 (2003)

= Conyza chilensis Spreng., Novi Provent.: 14 (1818)

Esta zamarraga es distinta por ser perenne, bastante alta ( $\pm 50-120 \mathrm{~cm}$ o más), y de inflorescencias laxamente ramificadas. Los capítulos son grandes, de unos $15 \mathrm{~mm}$ cuando están plenamente expandidos, el involucro hace unos (6)8-9(10) $\mathrm{mm}$ de largo. Las brácteas son densamente pubescentes, cubiertas de pelos cortos y blancos. Los tallos están revestidos de pocas hojas grandes $(10-18 \times 2-4 \mathrm{~cm})$ y con el margen crenado-dentado.

Aunque he recolectado esta planta recientemente en Guipúzcoa, País Vasco, no la he visto en estado silvestre en Cataluña. Hay pliegos de Sennen procedentes de las terrazas del río Besòs a su paso por uno de los municipios colindantes con Barcelona, con toda probabilidad Sant Adrià de Besòs, pero con su encauzamiento en tiempos recientes es de suponer que se haya extinguido de este paraje. Ha sido citada también de la comarca dels Serrans y de la Vall del Palància, de la Comunidad Valenciana. Nuestros pliegos indican una época de floración entre agosto y noviembre.

\section{Táxones conflictivos e híbridos}

Dentro del marco geográfico indicado en este trabajo existen, o han existido, plantas del género Conyza morfológicamente distintas de las indicadas arriba, reconocibles sin mucha dificultad, cuyo estatus (híbrido o no) y cuya presencia en el territorio hoy día requieren más investigación. Destacan dos táxones en este sentido: Conyza daveauana y C. $\times$ mixta, los dos poco frecuentes pero con bastante material de herbario. Estos vienen detallados más adelante.
Otros presuntos híbridos indicados de la región incluyen $C$. canadensis $\times C$. sumatrensis $[C$. $\times$ rouyana Sennen, nom. nud. (Tison \& Foucault, 2014)], $C$. bonariensis $\times C$. floribunda $[$ Erigeron $\times$ barcinonense Sennen] y el ya mencionado $C$. canadensis $\times$ C. floribunda [Erigeron $\times$ gonzaloi]. Más allá del territorio que nos concierne, otros han sido propuestos.

Estos híbridos putativos cuentan con pocos datos, una escasa evidencia de su presencia en tiempos recientes y, además, son difíciles de distinguir de sus progenitores. Debido a la variabilidad de las especies que constituyen este género, además de la circunscripción muy variada dada por los botánicos de táxones como $C$. bonariensis, sería de provecho verificar el concepto de híbrido con técnicas controladas de invernadero y el posterior contraste de los resultados con el material histórico.

Conyza daveauana Sennen in Bol. Soc. Aragonesa Ci. Nat. 11: 194 (1912)

$\equiv$ Erigeron daveauanus (Sennen) Greuter in Willdenowia 37: 142 (2007)

Se trata de un taxon poco recolectado en Cataluña en los últimos años. La mayoría de los testigos de herbario son antiguos. Al ser poco conocido, no figura en los trabajos más divulgados, probablemente por haber sido considerado un taxon híbrido. Aun siendo este el caso, tiene una morfología reconocible y, por tanto, merece una mayor atención y un estudio más profundo.

La planta, de 30-60(80) $\mathrm{cm}$, es menor que $C$. sumatrensis, con la cual comparte las hojas anchas de la parte basal del tallo $( \pm 3-6 \times 1-2 \mathrm{~cm})$, los márgenes de las cuales son crenado-dentados. Las hojas superiores, laxamente esparcidas por el tallo, en cambio, son enteras y más estrechas. Carece normalmente de fascículos axilares. La inflorescencia, de ramificación menos densa que en $C$. sumatrensis, contiene menos capítulos - un número muy reducido en algunas muestras-, éstos (vilano incluido) son un poco más grandes que los de $C$. sumatrensis en la fructificación, y con el vilano de color paja. Las brácteas tienen la banda mediana ancha y una pubescencia variable pero poca densa.

1. Hojas laxamente dispuestas por el tallo, sin hojas fasciculadas en las axilas, o con fascículos poco evidentes, las hojas basales cortas $(<50$ 


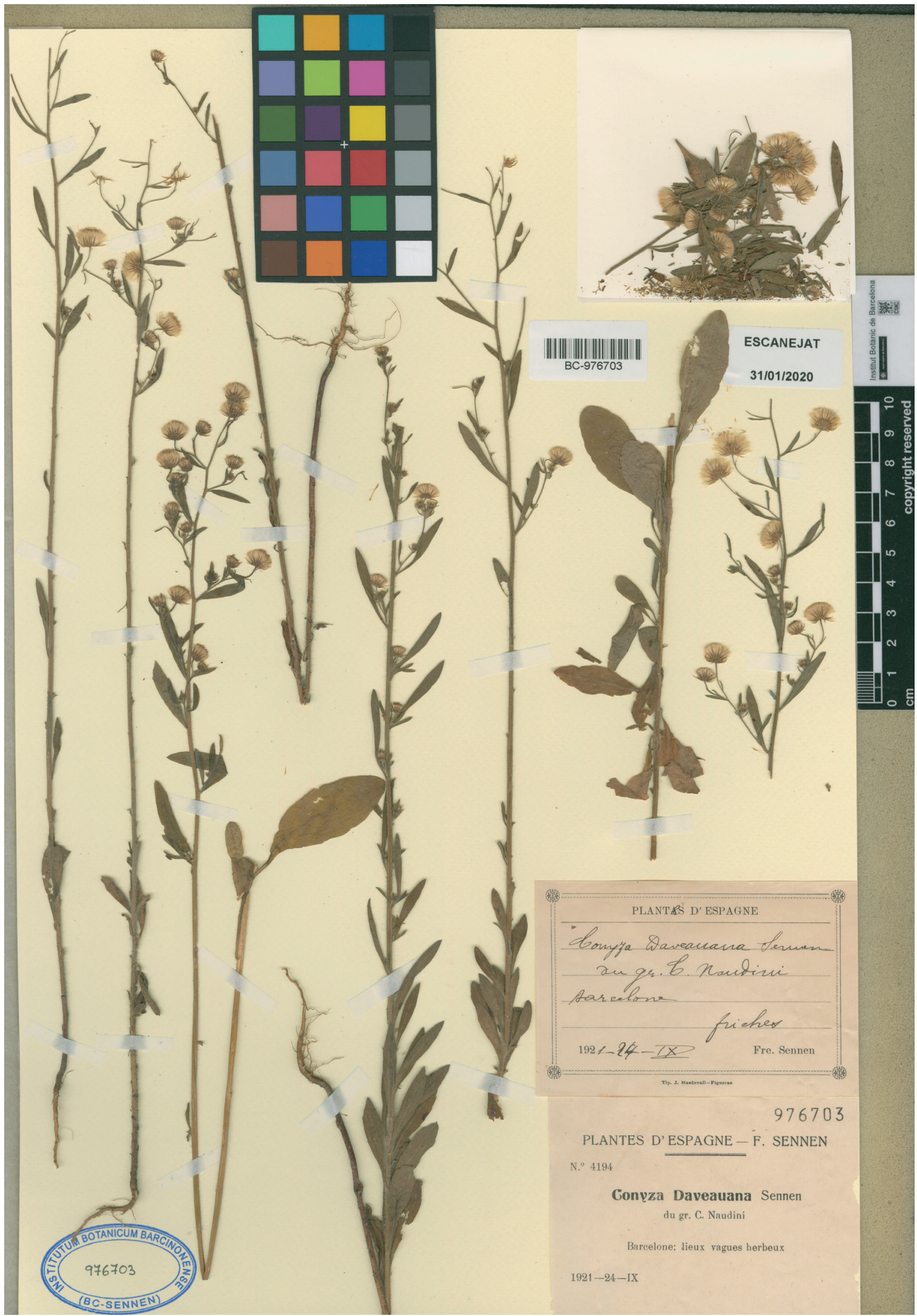

Figura 8. Conyza daveauana. Pliego de herbario de Sennen recolectado en Barcelona, septiembre 1921. 
$\mathrm{mm})$ y anchas (10-20 $\mathrm{mm})$, de margen crenato-dentado, las superiores enteras, 4-6 $\mathrm{mm}$ de ancho; inflorescencia abierta con relativamente pocos capítulos. Plantas poco frecuentes

\section{C. daveauana}

-. Hojas densamente dispuestas por el tallo, más grandes y con fascículos axilares evidentes; inflorescencia con numerosos capítulos. Plantas comunes, distribuidas por gran parte del territorio C. sumatrensis

Sennen (1912) inicialmente consideró que esta planta era el híbrido entre $C$. sumatrensis y $C$. bonariensis ( $u$ t " $C$. naudinii $\times C$. ambigua") pero, más adelante, parece que cambió de opinión, incluyéndola en el año 1921 en su "gr. Naudini" (entendemos C. sumatrensis sensu lato) y afirmando su taxon con una nueva descripción en Bol. Soc. Iber. Ci. Nat. 28: 70 (1929).

Habiendo visto mucho material atribuido por el mismo Sennen a este taxon, opino que podría tratarse de una variedad de $C$. sumatrensis. El cultivo experimental nos ayudaría a resolver las dudas. De los 14 pliegos conservados en BC y BC-Sennen y otros pliegos distribuidos por Sennen, algunos consultados telemáticamente (DAO457856, del año 1912; PH6593, de 1928), queda claro que el pliego (y, por tanto, sus duplicados) de "El Perthus (terr. espagn.)" (BC976512) es atípico, y no se debe escoger como lectótipo a pesar de la antigüedad de la fecha (1.X.1904). La muestra, de una inflorescencia incompleta, es de una planta algo más grande que lo habitual, atribuible a $C$. bonariensis, y en esto coincido con P. Jovet, cuya nota incluida en la muestra MPU23991 (del mismo lugar y fecha) indica que él había llegado a la misma conclusión. Por lo tanto, el concepto de $C$. daveauana (ya sea variedad o híbrido) se tiene que basar en el material síntipo de Collserola: "environs de Barcelone par les premières pentes du Tibidabo", el cual es compatible con el protólogo (donde menciona tanto El Perthus como Barcelona) y corresponde al concepto que tenía Sennen de su taxon durante la mayor parte de su vida activa. En el protólogo se lee que el involucro y las hojas se asemejan más a "Naudini" (C. sumatrensis), y esto es el caso en la gran mayoría de las muestras de Sennen. Las brácteas individuales de estas corresponden a $C$. sumatrensis y no a $C$. bonariensis. Nesom (2018) llegó a la misma conclusión e incluyó $C$. daveauana en la sinonimia de C. sumatrensis.
Es una planta de distribución dispersa por la costa catalana. Sennen la conoció del Alt Empordà y de las faldas de Collserola (Barcelona), de donde hay bastante material. En los herbarios consultados hay los pliegos determinados por Sennen, y además, unos pocos pliegos que, a mi juicio, corresponden a este taxon, de localidades del entorno de Barcelona, de la Serralada de Montnegre, las estribaciones de Montseny, el Maresme y también de Els Ports (Tarragona). Según Flora valentina (Mateo et al., 2013) se encuentra también en las zonas costaneras de la Comunidad Valenciana. Florece en el otoño.

Conyza $\times$ mixta Fouc. \& Neyr. in Ann. Soc. Sci. Nat. Charente-Infer. 110 (1902)

$\equiv$ Erigeron $\times$ foucaudii B. Bock in Bull. Soc. Bot. Centre-Ouest 42: 263 (2012)

$=$ Conyza $\times$ flahaultiana Sennen in Bol. Soc. Aragonesa Ci. Nat. 4: 319 (1905) E Erigeron flahaultianus (Sennen) Thell. in Mém. Soc. Sci. Nat. Math. Cherbourg 38: 499 (1912)

Es esta una planta que puede alcanzar 1,5-2 $\mathrm{m}$ de altura, con hojas \pm lineares de 2-6(9) $\mathrm{mm}$ de anchura y una panícula tirsoide de ramificación más bien monopodial. El síntipo de Rochefort (Charente-inférieure, France, Nº743, MPU24003) nos da una idea del aspecto de este híbrido, descrito por los franceses Foucaud y Neyraut. En el material de Sennen estudiado (con corola interna de cinco lóbulos y lígulas externas de longitud menor de 0,5 $\mathrm{mm})$, no se aprecian los caracteres de diagnóstico de $C$. canadensis, uno de sus supuestos progenitores $(C$. bonariensis $\times C$. canadensis $)$, pero se trata de observaciones hechas en el herbario. Faltan nuevas recolecciones, ya que es interesante estudiar estos detalles en plantas vivas. No hemos de olvidar que los caracteres morfológicos suelen ser muy variables en los híbridos. Nesom (2018) incluye $C$. $\times$ flahaultiana dentro de su concepto de $C$. sumatrensis, sin relacionar aquel con el taxon de Foucaud \& Neyraut. Al revisar los pliegos indicados en el apéndice, discrepo con su conclusión, y doy apoyo, más bien, al origen híbrido de estas plantas. Un estudio molecular puede que sea más determinante.

Hay algunas muestras antiguas recolectadas en Cataluña antes de 1925 (véase Apéndice), pero no he visto testigos de herbario que avalen su presencia en territorio ibérico en tiempos más recientes. Con todo, este híbrido ha sido mencionado del 
interior de la Comunidad Valenciana (Mateo et al., 2013) y es el que aparece en Morales (2019).

\section{DISCUSIÓN}

Las zamarragas muestran una gran capacidad de adaptación a diferentes entornos: tierras labradas o removidas, grietas en construcciones como muros o entre rocas, márgenes de bosques, caminos, apartaderos ferroviarios, carreteras, céspedes, huertas y prados poco cuidados. En Cataluña, la aparición y desaparición de las diferentes especies plantea interrogantes. El cambio climático bien podría haber contribuido, al menos en parte, a la recesión de $C$. floribunda, y podemos postular una consecuente proliferación de C. sumatrensis y de la recién llegada C. canadensis var. glabrata, a sus expensas, por estar estas últimas mejor adaptadas al incremento térmico registrado en la región costera de Cataluña en las últimas décadas. La distribución de C. floribunda en la región neotropical sigue las tierras relativamente elevadas — no muy cálidas - de las cordilleras.

Conyza canadensis var. glabrata muestra un patrón de expansión semejante a otra compuesta norteamericana de la misma tribu Astereae, Heterotheca subaxillaris (Lam.) Britton \& Rusby, la cual en pocos años se ha ido extendiendo por la Región Mediterránea, formando grandes poblaciones en Marruecos (Pyke et al., 2008) y en el Levante mediterráneo (Bou Dagher-Kharrat et al., 2016). En su continente de origen esta planta, Camphorweed en inglés, comparte una distribución semejante a la del taxon que nos ocupa aquí.

Conyza es claramente un grupo crítico de plantas. Aunque en Europa tenemos pocas especies representadas, al estar lejos del epicentro del género, no deja de ser un género de taxonomía complicada, como manifiestan los muchos sinónimos, aplicados de manera incorrecta en algunas ocasiones. Esta situación se debe, por un lado, a la variabilidad dentro de la misma especie, y por otro, a la presencia de híbridos. A pesar de la existencia de híbridos, en general se puede observar plantas de una morfología bastante estable en las poblaciones presentes en Europa, lo que se traduce en la aceptación de unas cuatro o cinco especies, según el país, en los trabajos florísticos de varios países del continente.

El estudio cuidadoso de los protólogos, holótipos y lectótipos en los últimos años, facilitado por la tecnología actual, ha servido para aclarar algunas de las dudas. Aun así, no hay acuerdo en lo que se refiere a la identidad de algunas piezas claves de los herbarios históricos. En cuanto a la interpretación de los sinónimos, los comentarios ya hechos sirven para subrayar las dificultades a la hora de interpretar el material histórico.

La confusión sobre la identidad de $C$. bonariensis parece remontarse a Willdenow, según Burtt (1948). El concepto que tuvo Willdenow del taxon habrá influido a Cuatrecasas (1969), cuyo tratamiento en Prima Flora Colombiana reunió los tres táxones que en este trabajo he llamado C. bonariensis, C. floribunda y C. sumatrensis, subordinando los últimos dos (en categorías infraespecíficas) bajo su C. bonariensis sensu lato. D'Arcy (1975) sigue a Cuatrecasas, pero con una diferencia. La descripción de D’Arcy (1975) de C. bonariensis para Flora of Panama (departamento de Colombia antes de 1903) corresponde a $C$. floribunda y $C$. sumatrensis, ambos táxones extendidos por el país vecino según Cuatrecasas. Lo que resulta extraño es que D'Arcy parece ignorar la planta que corresponde a $C$. bonariensis s. str., cuyo tipo él mismo menciona (Herb. Linn. 994.11) en el mismo trabajo. Tanto en la descripción como en la clave de especies (p. ej.: "upper leaves narrow but not linear"); este autor comunica una idea de $C$. bonariensis que no corresponde ni a la de Cabrera ni al tipo que menciona pero reconoce no haber visto. Morales (2019) también adopta este tratamiento sintético. La postura de minimizar el número de táxones (lumping, en inglés) tiene sus defensores, ya que el género es especialmente complicado en la región entre Méjico y el Cono Sur de Sudamérica.

No obstante, otros autores ya mencionados, como Cabrera (1974), Stace (2010) o Nesom (2018), optan por reconocer un mayor número de especies, postura que he seguido. Se ve, pues, que la literatura refleja nuestra comprensión incompleta de este género, siendo necesaria una consulta cuidadosa de los diversos trabajos publicados a lo largo de más de dos siglos, junto con el estudio de los tipos, híbridos incluidos. Para poder entender mejor estas plantas hemos de hacer más trabajo de campo, observando atentamente las poblaciones y su dinamismo. Aún queda trabajo por hacer. 


\section{AGRADECIMIENTOS}

Al personal de CeDocBiV, Plant Biodiversity Resource Centre, Universidad de Barcelona; también a T. Casasayas, y a J. Font por sus comentarios sobre Conyza en la provincia de Girona. A P. Álvarez del Col·legi La Salle, Bonanova, por facilitar la consulta del material del género Conyza del herbario Sennen, La Salle, Barcelona. Mis agradecimientos a D. Muñiz y A. Romo por revisar el castellano, a J. Molero por su empuje inicial, y a A. Susanna y dos revisores anónimos por sus comentarios destinados a mejorar la presentación del trabajo. Al Consejo Superior de Investigaciones Científicas (Spanish National Research Council) por proveerme el acceso a Ithaka digital technology (JSTOR) y a otros recursos.

\section{BIBLIOGRAFÍA}

Aizpuru, I., Aseginolaza, C., Uribe-Echebarría, P. M., Urrutia, P. \& Zorrakin, I. 1999. Claves ilustradas de la Flora del País Vasco y territorios limitrofes. Servicio Central de Publicaciones del Gobierno Vasco, Vitoria-Gasteiz.

Bolòs, A. de 1950. Vegetación de las comarcas barcelonesas. Instituto Español de Estudios Mediterráneos, Barcelona.

Bolòs, O. de \& Vigo, J. 1984-2001. Flora dels Països Catalans 1-4. Editorial Barcino, Barcelona.

Bolòs, O. de \& Vigo, J. 1996. Flora dels Països Catalans 3. Editorial Barcino, Barcelona.

Bou Dagher-Kharrat, M., Farhat, P., Dakik, N., Kahale, R. \& Potash, L. 2016. Invasion and management of Heterotheca subaxillaris in Tyre Coast Nature Reserve, Lebanon. Poster presented at the 1st Mediterranean Plant Conservation Week (Ulcinj, Montenegro, 24-29 October 2016).

Britton, N. L. 1914. On Erigeron pusillus Nutt. Torreya 14: 197-199. https://doi.org/10.1002/asna.19141991403

Burtt, L. 1948. On Erigeron bonariensis Linn. Kew Bulletin 3: 369-372. https://doi.org/10.2307/4108843

Cabrera, A. L. 1974. Conyza Less. In: Burkart, A. (Ed.), Flora ilustrada de Entre Ríos (Argentina) 6: 219-228. Colección Científica del I.N.T.A., Buenos Aires.

Casasayas, T. 1989. La flora al lòctona de Catalunya. Tesis Doctoral, Universitat de Barcelona, Barcelona.

Castroviejo, S. (Coord.) 1986-2019. Flora iberica. Plantas vasculares de la Peninsula Ibérica y Baleares. Real Jardín Botánico (CSIC), Madrid.

Cuatrecasas, J. 1969. Prima Flora Colombiana: Compositae - Astereae. Webbia 24: 1-335. https://doi.org/10.1080/0 0837792.1969 .10669907

D'Arcy, W. G. 1975. Astereae: Conyza. In: Woodson, R. E. \& Schery, R. W. (Eds.), Flora of Panama. Annals of the Missouri Botanical Garden 62: 1020-1025.

González-Martínez, X. I. 2015. Contribución al conocimiento de la flora alóctona de Galicia. Botanica Complutensis 39: 79-85. https://doi.org/10.5209/rev_BOCM.2015. v39.49136

Greuter, W. 2003. The Euro+Med treatment of Astereae (Compositae) - generic concepts and required new names. Willdenowia 33: 45-47. https://doi.org/10.3372/ wi.33.33103

Greuter, W. 2006- Compositae (pro parte majore). In: Greuter, W. \& Raab-Straube, E. von (Ed.), Compositae.
Euro +Med Plantbase - the information resource for Euro-Mediterranean plant diversity. Botanic Garden and Botanical Museum, Berlin-Dahlem. Retrieved July 5, 2019, from http://ww2.bgbm.org/EuroPlusMed/. https:// doi.org/10.3372/wi.36.36206

Laínz, M. 2002. Conyza blakei (Cabrera) Cabrera (Compositae), ¿especie peninsular? Anales del Jardín Botánico de Madrid 59: 352-353.

Malagarriga, T. 1965. Flora analitica de Barcelona. La Salle Bonanova, Barcelona.

Marshall, J. B. 1974. A note on Conyza sumatrensis (Retz) E. Walker (C. floribunda). Watsonia 10: 166-167.

Mateo, G., Crespo, M. B. \& Laguna, E. (Eds.) 2013. Flora valentina 2. Fundación de la Comunitat Valenciana para el Medio Ambiente, Valencia.

Morales, R. 2019. Conyza Less. In: Benedí, C., Buira, A., Rico, E., Crespo, M. B., Quintanar, A. \& Aedo, C. (Eds.), Flora iberica 16. Real Jardín Botánico (CSIC), Madrid: 2022-2027.

Nesom, G. 2008. Classification of subtribe Conyzinae (Asteraceae: Astereae). Lundellia 11: 8-38. https://doi. org/10.25224/1097-993X-1.11.8

Nesom, G. 2018. Erigeron floribundus and E. sumatrensis (Asteraceae) in the USA and Mexico. Phytoneuron 2018-27: 1-19.

Noyes, R. D. 2000. Biogeographical and evolutionary insights on Erigeron and allies (Asteraceae) from ITS sequence data. Plant Systematics and Evolution 220: 93-114. https://doi.org/10.1007/BF00985373

Pruski, J. F. \& Sancho, G. 2006. Conyza sumatrensis var. leiotheca (Compositae: Astereae), a new combination for a common neotropical weed. Novon 16: 96-101. https://doi. org/10.3417/1055-3177(2006)16[96:CSVLCA]2.0.CO;2

Pyke, S., Michaud, H., Ferrer, P., Argagnon, O., Virevaire, M. \& Montserrat, J. 2008. Notes on vascular plants in Morocco. Lagascalia 28: 473-480.

Qureshi, R. \& Raana, S. 2013. Conyza sumatrensis (Retz.) E. H. Walker: A new record from Pakistan. Plant Biosystems 148: 1035-1039. https://doi.org/10.1080/11263504 .2013 .850119

Rand, M. 2008. Difficulties with Conyza (Fleabanes). BSBI News 108: 40-43.

Sennen, F. 1904. Note sur le Cirsium corbariense Sennen, sur le Conyza naudini Bonnet et sur quelques hybrides. Bulletin de la Société Botanique de France 51: 425-426. https://doi.org/10.1080/00378941.1904.10829148

Sennen, F. 1912. Quelques formes nouvelles ou peu connues de la flore de Catalogne, Aragón, Valence. Boletín de la Sociedad Aragonesa de Ciencias Naturales 11: 194-195.

Stace, C. 2010. New Flora of the British Isles (3rd ed.; 2015 reprint). Cambridge University Press, Cambridge.

Stace, C. \& Crawley, M. J. 2015. Alien plants. Collins, London.

Thébaud, C. \& Abbot, R. 1995. Characterization of invasive Conyza species (Asteraceae) in Europe: quantitative trait and isozyme analysis. American Journal of Botany 82: 360-368. https://doi.org/10.1002/j.1537-2197.1995. tb12640.x

Tison, J. M. \& de Foucault, B. 2014. Flora Gallica Flore de France. Biotope, Mèze.

Tison, J. M., Jauzein, P. \& Michaud, H. 2014. Erigeron. In: Tison, J. M., Jauzein, P. \& Michaud, H. (Eds.), Flore de la France méditerranéenne continentale. Naturalia $\mathrm{Pu}-$ blications, Turriers: 1502-1507. 
Tutin, T. G., Heywood, V. H., Burges, N. A., Moore, D. M., Valentine, D. H., Walters, S. M. \& Webb, D. A. (Eds.) 1976. Flora Europaea 4. Cambridge University Press, Cambridge. Tuyama, T. \& Asai, Y. 1967. On the true status of Erigeron canadensis L. var. levis Makino. Journal of Japanese Botany 42: 335-342.

Urdampilleta, J. D., Amat, A. G. \& Bidau, C. J. 2005. Karyotypic studies and morphological analysis of some reproductive features in five species of Conyza (Astereae: Asteraceae) from North-eastern Argentina. Boletín de la Sociedad Argentina de Botánica 40: 91-99.
Verloove, F. 2016. Manual of the alien plants of Belgium. Botanic Garden Meise, Meise. Retrieved July 16, 2019, from http://alienplantsbelgium.be/content/ erigeron-floribundus\#overlay-context=content/erigeron-floribundus

Verloove, F. \& Sánchez Gullón, E. 2008. New records of interesting xenophytes in the Iberian Peninsula. Acta Botanica Malacitana 33: 147-167. https://doi.org/10.24310/abm. v33i0.6978

Wurzell, B. 1988. Conyza sumatrensis (Retz.) E. Walker established in England. Watsonia 17: 145-148. 
Apéndice. Selección de pliegos que avalan los táxones críticamente evaluados. Nota: Hb Sennen: ubicación BC.; LS = Herbario La Salle Bonanova, Barcelona.

C. bonariensis var. angustifolia ( $\sin$ variedad o $u t$ C. ambigua), me judice.

Barcelona: Barcelona, friches, 16.IX.1921, Sennen s/n (Hb Sennen); Montseny, Sant Pere de Vilamajor, VIII.1931, P. Font Quer (BC81736); Barcelona, Pedralbes, 29.X.1939, A. de Bolòs (BC100547); Òrrius, torrent de Can Fum, 20.VIII.1945, P. Montserrat (BC930613); Esparreguera, Mas d'en Gall, camps incultes, 28.VIII.1969, J. Banau i Andreu [Hno. Gonzalo] (BC942830) con material de C. sumatrensis recolectado en la misma ocasión. Castelló: Almassora al Grau, 31.VIII.1954, Caldrich (BC128794).

Nota: Hay también pliegos de Andalucía y Portugal en $\mathrm{BC}$ referibles a este taxon.

\section{C. canadensis var. glabrata}

Barcelona: L'Hospitalet de Llobregat, Gran Via Sur, 31T DF2678, $10 \mathrm{~m}$, 18.IX.2013, S. Pyke (BC932025); El Prat de Llobregat, Cases dels Carabiners, 31T DF2672, 5 m, 30.IX.2013, S. Pyke (BC932604); Talamanca, margen de la carretera hacia Navarcles, 31T DG1421, 560 m, 24.IX.2014, S. Pyke (BC940039); Barcelona, Gran Via, La Campana, descampat, 31T DF2779, 5 m, 3.X.2014, C. Gómez Bellver (BC879483); Manlleu, estación ferroviaria, 31T DG3950, 460 m, 31.VIII.2019, S. Pyke (SBP7762); Castelldefels, dunes litorals, 31T DF1268, $5 \mathrm{~m}$, 24.IX.2019, S. Pyke (SBP7772). Girona: Fortià, Rec dels Piconers, herbazales viarios y márgenes de campos de regadío, 31T EG0377, $5 \mathrm{~m}, 18$.VIII.2007, $S$. Pyke (BC907002); La Jonquera, herbazales viarios, 31T DG8997, 120 m, 5.X.2013, S. Pyke (BC932608). Tarragona: Carretera a Picamoixons, ruderal-viària, marge de la carretera, 31T CF47, 210 m, 17.IX.2015, J. Molero \& S. Pyke (BC879949).

N.B. También hay un pliego antiguo de la Comunidad Valenciana atribuible a esta variedad (ut Erigeron canadensis L.): Corbera de Alcira, XI.1944, J. Borja (BC95813).

C. floribunda (pliegos anteriores al año 1927 ut Erigeron coronopifolius Sennen)

Barcelona: [sin precisar municipio], plaine du Llobregat, X.1910, Sennen (BC31803); [sin precisar municipio], plaine du Besòs, 10.IX.1914, Sennen (BC31815, BCN35244); Barcelona, massif du Tibidabo, éboulis vers las Planas, 2.XI.1918, Sennen (BC31817); Barcelona, á Valdoncellas [Valdonze1la], lieux vagues, $450 \mathrm{~m}$, 8.IX.1921, Sennen (Hb Sennen $\mathrm{s} / \mathrm{n}$ ); Barcelona, Tibidabo á Vallvidrera, apeadero, 16.IX.1921, Sennen (Hb Sennen s/n); Manlleu, décombres, marges [ \pm 450 m] 3.X.1923, Hno. Gonzalo (BC31816); Manlleu, bords du canal, 450 m, 6.IX.1927, ut C. rouyana Sennen, Hno. Gonzalo (BCN58856); Barcelona, carrer Ganduixer, 19.XI.1933, Sennen ex Hb J. Darder (BCN73096); Barcelona, Les Planes, 7.XII.1933, Sennen ex Hb J. Darder (BCN73100); Pineda, Can Verd, a prop de la riera de Pineda, 24.IX.1945, P. Montserrat (BC626265); Sant Celoni, àrea d'autopista, 31T DG51, 16.VII.1985, ut C. blakei (Cabrera) Cabrera, T. Casasayas (BCN67993); Tordera, 31T DG71, 22.V.1988, A. Farràs (BCN34768). Girona: Massanet de la Selva, 5.VI.1920, P. Font Quer (BC143425); Pont de Molins, llit de la Muga, 31T DG98, 2.XI.1985, ut C. blakei (Cabrera) Cabrera, T. Casasayas (BCN67993). Tarragona: Xerta, Assut de Xerta, 31T BF83, 20 m, 11.XII.1998, F. Royo (BCN13474).

\section{C. primulifolia (ut C. chilensis Spreng.)}

Barcelona: [sin precisar municipio], marges de Besòs, 3.IX.1920, Sennen (BC31852, BC140466, BCN34852 y Hb. Sennen s/n).

C. daveauana (ut gr. C. naudinii, C. naudinii $\times$ C. ambigua, C. sumatrensis ...)

Barcelona: Barcelona, barranco de Penitents, 1.XI.1914, Sennen (BC31850, LS12512); Barcelona, Sant Gervasi, chemins, haies, torrents, XI.1915, Sennen (BC31849, LS12502); Barcelona, lieux vagues herbeux, 24.IX.1921, Sennen (BC31851, LS12496); Montseny, Sant Pere de Vilamajor, VIII.1931, P. Font Quer (BC143427); Argentona, Aiguaneix de Ballot, lloc humit, 11.IX.1944, P. Montserrat (BC805800); Tiana, La Conreria, prop als edificis, 31T DF3793, $320 \mathrm{~m}$, 9.VI.2002, S. Pyke (BC866238). Tarragona: Alfara de Carles, Lo Toscar, 31T BF72, 500 m, 16.IX.2002, F. Royo (BCN13476).

\section{C. ×mixta (incl. C. ×flahaultiana)}

Francia. Charente-Inférieure: Rochefort, lieux vagues du jardin botanique, août et septembre 1901, J. Foucaud (Hb. Sennen No4743). 
España. Barcelona: Vilarnadal et Cabanas, Champs, Oct.-Nov. 1905, 1906, ut C. ×flahaultiana, Sennen (Hb Sennen No164); Cabanas, pelouses, 21.IX.1906, ut C. ×mixta Fouc. \& Neyr. (= C. ambigua $\times$ E. canadensis), Sennen (LS12507); [sin precisar municipio] environs de Barcelona, Plaine du Llobregat, 1.X.1910, Sennen (LS12505); Barcelona, lieux vagues "inter parentes", 5.X.1912, ut C. ×flahaultiana Sennen, Sennen (Hb Sennen s/n); Barcelona, vers Valdoncellas, lieux vagues, 8.IX.1921, $u t ~ " C$. $f l a-$ haultiana Sennen $=E$. canadense $\times C$. ambigua", Sennen (Hb Sennen No4232, BC31855); Castelldefels, "inter parentes", 7.IX.1923, ut E. flahaultianus (Sennen) Thell., Sennen (Hb Sennen s/n); Prat del
Llobregat, sables herbeux, 13.VIII.1925, ut E. flahaultianus (Sennen) Thell. $=$ E. canadensis $\times \mathrm{E}$. crispus ej., Sennen (Hb Sennen s/n). Girona: Llers, Els Hostalets, environs de Figueras aux Hostalets, champs, 2.X.1904, ut ?C. mixta Fouc. \& Neyr., Sennen (Hb Sennen) [Nota del autor: parece C. bonariensis var. angustifolia].

Consultados también (BC, BCN): pliegos muy numerosos de $C$. canadensis var. canadensis (ut $C$. canadensis), C. bonariensis var. bonariensis (ut C. bonariensis y sinónimos usuales) y $C$. sumatrensis (diversas determinaciones). Por el volumen de material, no vienen indicados aquí. 